\title{
Efficacy of Sofosbuvir Plus Ribavirin with and without Pegylated Interferon-A in Patients with HCV Genotype 3A Infection
}

\author{
MUSTAFA KAMAL ${ }^{1}$, ARSALAN JAMIL RAJA ${ }^{2}$, TANVEER AHMED ${ }^{3}$, MASHHOOD ALI ${ }^{4}$, FAISAL RASHEED ${ }^{5}$ \\ ${ }^{1}$ Consultant Gastroenterologist, District Hospital Sawabi \\ ${ }^{2}$ Assistant Professor of Gastroenterology, Department of Gastroenterology, Bahawal Victoria Hospital, Bahawalpur \\ ${ }^{3}$ Consultant Gastroenterologist, Bahawal Victoria Hospital, Bahawalpur \\ ${ }^{4}$ Head of Department of Gastroenterology, Pakistan Institute of Medical Sciences, Shaheed Zulfiqar Ali Bhutto Medical University, \\ Islamabad. \\ ${ }^{5}$ Breath MAT Lab, Pakistan Institute of Nuclear Science and Technology, Islamabad \\ Correspondence: Dr. Tanveer Ahmed, Email; ahmedtanveer17@yahoo.com, Contact\# 03327201463
}

\begin{abstract}
Background: Hepatitis C virus (HCV) infection is a serious problem in low and middle income countries including Pakistan.

Objective: To compare the efficacy of combination therapy, Sofosbuvir plus Ribavirin with and without Pegylated Interferon- $\alpha$ in HCV genotype $3 a$ infected patients.

Study Design: Randomized control trial

Place and Duration: Department of Gastroenterology, Pakistan Institute of Medical Sciences (PIMS), Islamabad, during from 16th April 2017 to 15th October 2017.

Methodology: One hundred and fifty four HCV infected patients with genotype 3a were included in this study. Detailed demographics were recorded after taking informed written consent. Patients were divided in two groups (A and B) randomly, Group A was offered with Sofosbuvir plus Ribavirin with Pegylated Interferon- $\alpha$ for 12 weeks and Group B was offered with Sofosbuvir plus Ribavirin for 24 weeks. The sustained virological response (SVR) after 12 weeks of therapy was compared between the study groups.

Results: The frequency of SVR12 was comparatively higher in patients treated with Sofosbuvir plus Ribavirin with Pegylated Interferon- $\alpha$ (94.8\%) than Sofosbuvir plus Ribavirin alone (84.4\%) with similar trends in gender and age groups.

Conclusion: The combination therapy Sofosbuvir plus Ribavirin with Pegylated Interferon-a had higher eradication rate against HCV genotype $3 a$ in our local setting.

Key Words: HCV, genotype 3a, Sofosbuvir, Ribavirin, Pegylated Interferon-a, SVR12
\end{abstract}

\section{INTRODUCTION}

Hepatitis C virus (HCV) infection is a serious health problem, worldwide and $80 \%$ of the HCV burden is concentrated in low and middle income countries (Graham CS, et al., 2015) [2]. In Pakistan, $~ 5 \%$ of the population are infected with HCV infection (Ahsan A, et a., 2019) [1] but most are unaware of their infection.

The use of interferon-based therapy has made HCV eradication challenging and efficacy of Sofosbuvir based antiviral regimens has shown promising results in achieving SVR in chronic HCV infected patients [3]. In EASL guidelines treatment recommended for HCV Genotype 3 is as follows; Sofosbuvir plus Ribavirin for 24 weeks and Sofosbuvir plus Ribavirin with Pegylated Interferon- $\alpha$ for 12 weeks [4]. The study was aimed for the efficacy of Sofosbuvir plus Ribavirin with and without Pegylated Interferon- $\alpha$ in chronic Hepatitis $\mathrm{C}$ genotype 3a patients.

\section{MATERIALS AND METHODS}

Patients (age: 20-60 years) attending Department of Gastroenterology, Pakistan Institute of Medical Sciences (PIMS), Islamabad diagnosed with Hepatitis C viral load with genotype 3a were enrolled. The patients, who were not previously treated with any antiviral regimen, having no other comorbid conditions and no renal derangements were included. Patients with below $90,000 / \mu$ l platelets and hemoglobin $12 \mathrm{~g} / \mathrm{dl}$ were excluded from the study. The study was approved by Ethical Review Board, PIMS and informed written consent was obtained from each patient.
All patients were subjected to full history intake, thorough physical examination and the following laboratory test measurements: serum ALT, albumin, total bilirubin, prothrombin time and concentration, complete blood count, renal function test, thyroid profile, random blood sugar, HCV RNA by quantitative polymerase chain reaction (PCR), HCV RNA Genotype, abdominal ultrasonography, ECG before and after treatment. Additionally, complete blood picture, renal function test and liver function tests were monitored weekly during treatment.

Patients were divided in two groups (A and B) randomly, Group A was offered with Sofosbuvir plus Ribavirin with Pegylated Interferon- $\alpha$ for 12 weeks and Group B was offered with Sofosbuvir plus Ribavirin for 24 weeks. Patients were followed on monthly basis and at the end of treatment, HCV quantitative PCR was advised and repeated after 12 weeks for monitoring of sustained virological response (SVR).

All the collected data was entered and analyzed through SPSS version 20.0. The frequency of SVR has been compared among the study groups using Chi-square test at a significance level of $p<0.05$.

\section{RESULTS}

There were 107 (69.48\%) males (group A 55, group B 52) while $47(30.52 \%)$ patients were females (group A 22 , group B 25). (figure 1)

Majority $70(45.45 \%)$ patients were ages between 31 to 40 years followed by $32(20.78 \%)$ were ages between 41 
to 50 years, $26(16.88 \%)$ had ages above 50 years and 26 $(16.88 \%)$ were ages between $\leq 30$ years. (Table 1 )

Figure No 1: Gender wise distribution among both groups

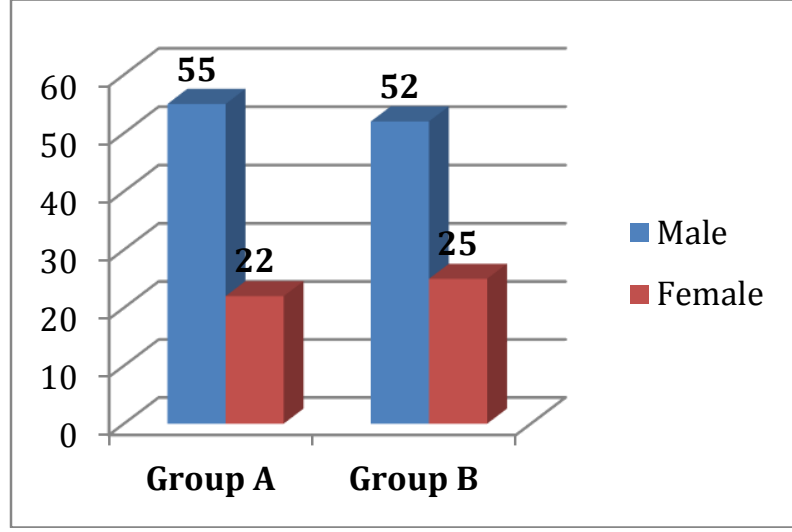

Table No 1: Age wise distribution among both groups

\begin{tabular}{|l|l|l|l|}
\hline Variables & $\begin{array}{l}\text { Group A } \\
(n=77)\end{array}$ & $\begin{array}{l}\text { Group B } \\
(n=77)\end{array}$ & $\begin{array}{l}\text { Total } \\
(n=154)\end{array}$ \\
\hline$<30$ years & $13(16.88)$ & $13(16.88)$ & $26(16.88)$ \\
\hline 31 to 40 years & $34(44.16)$ & $36(46.75)$ & $70(45.45)$ \\
\hline 41 to 50 years & $17(22.08)$ & $15(19.48)$ & $32(20.78)$ \\
\hline Above 50 years & $13(16.88)$ & $13(16.88)$ & $26(16.88)$ \\
\hline Total & $77(100)$ & $77(100)$ & $154(100)$ \\
\hline
\end{tabular}

The frequency of SVR12 was higher in patients treated with Sofosbuvir plus Ribavirin with Pegylated Interferon- $\alpha(94.8 \%, 73 / 77)$ as compared to Sofosbuvir plus Ribavirin (84.4\%, 65/77). Similar trends were noted across various age and gender groups with non significant difference (Table 2).

Table 2: Comparison of frequency of SVR12 between the study groups across age groups

\begin{tabular}{|l|l|l|l|}
\hline & $\begin{array}{l}\text { SVR12 using } \\
\text { Sofosbuvir plus } \\
\text { Ribavirin with } \\
\text { Pegylated Interferon- } \alpha \\
\text { frequency \% (n/total) }\end{array}$ & $\begin{array}{l}\text { SVR12 using } \\
\text { Sofosbuvir plus } \\
\text { Ribavirin } \\
\text { frequency \% } \\
\text { (n/total) }\end{array}$ & $\begin{array}{l}p \\
\text { value }\end{array}$ \\
\hline Gender & & & \\
\hline Male & $94.5 \%(52 / 55)$ & $84.6 \%(44 / 52)$ & 0.091 \\
\hline Female & $95.5 \%(21 / 22)$ & $84.0 \%(21 / 25)$ & 0.204 \\
\hline $\begin{array}{l}\text { Age } \\
\text { (years) }\end{array}$ & & & \\
\hline$\leq 30$ & $92.3 \%(12 / 13)$ & $84.6 \%(11 / 13)$ & 0.539 \\
\hline $31-40$ & $97.1 \%(33 / 34)$ & $83.3 \%(30 / 36)$ & 0.056 \\
\hline $41-50$ & $94.1 \%(16 / 17)$ & $86.7 \%(13 / 15)$ & 0.471 \\
\hline$\geq 51$ & $92.3 \%(12 / 13)$ & $84.6 \%(11 / 13)$ & 0.539 \\
\hline
\end{tabular}

\section{DISCUSSION}

Hepatitis $\mathrm{C}$ is one of the leading causes of death in Pakistan due to end stage liver disease. Chronic HCV infection affects an estimated 170 million people all over the world with a prevalence of approximately $8-10 \%$ in Pakistan [5-6]. Hepatitis C is heterogeneous virus with several genotypes. The HCV genotypes 1-3 are distributed worldwide, whereas in Pakistan genotype $3 a$ is the most common type [7-8] Sofosbuvir plus Ribavirin combination is routinely used against the HCV Genotype 3 infection in Pakistan [9]. However, recent studies claimed triple therapy consisting of Sofosbuvir plus Ribavirin along with Pegylated Interferon- $\alpha$ to be associated with higher frequency of SVR after 12 weeks of therapy [10]. Yet there was controversy in the existing studies [10-15] while there was no such local published material which necessitated the present study.

In the current study, the frequency of SVR12 was higher in patients treated with Sofosbuvir plus Ribavirin with Pegylated Interferon- $\alpha \quad(94.8 \%$ vs. $84.4 \%)$ as compared to Sofosbuvir plus Ribavirin. Similar difference was noted across various age and gender groups. Our results are comparable to those of Akhter et al. (2016) who reported the frequency of SVR12 to be $85.5 \%$ with Sofosbuvir + Ribavirin alone at Holy Family Hospital, Rawalpindi [13]. Zeuzem et al. (2014) reported similar frequency of SVR12 (85.0\%) with Sofosbuvir plus Ribavirin alone in UK [12]. Shah et al. (2016) reported much higher frequency of SVR12 (93.0\%) with Sofosbuvir plus Ribavirin alone in Indian patients with HCV genotype 3 infection [14]. Our results are comparable to those of Foster et al. (2015) who also reported similar significantly higher frequency of SVR12 with triple therapy (93.0\% vs. 84.0\%) in UK [10]. Similar results have also been reported by Ahmed et al. (2017) in Egyptian patients who reported frequency of SVR12 to be $94.0 \%$ with triple therapy as compared to $83.0 \%$ with dual therapy [11]. Konar et al. (2016) reported similar difference $(92.9 \%$ vs. $88.5 \%)$ in Indian population [15].

Additionally, we observed that the mean age of the patients in our population was quite younger as compared to other populations which might be related to diversity of viral genotype. It may additionally be due to differences in the educational status, living standards, healthcare malpractice and drug abuse. It thus warrants necessary changes in healthcare policy to control this deadly condition in the young population.

The present study is first of its kind in local population and adds to the limited research evidence on this topic. The results of the present study are in line with the previously published evidence and establish the higher efficacy of triple therapy consisting of Sofosbuvir plus Ribavirin with Pegylated Interferon- $\alpha$. It can be thus advocated that this triple therapy should be preferred in future practice to increase the likelihood of SVR12.

\section{CONCLUSION}

We concluded that the combination therapy consisting Sofosbuvir plus Ribavirin with Pegylated Interferon- $\alpha$ was found to be associated with higher frequency of SVR12 as compared to Sofosbuvir plus Ribavirin alone in patients infected with HCV genotype $3 \mathrm{a}$.

\section{REFERENCES}

1. Ahsan A, Khan AZ, Javed H, Mirza S, Chaudhary SU, Shahzad-Ul-Hussan S. Estimation of hepatitis C prevalence in the Punjab province of Pakistan: A retrospective study on general population. PLoS One. 2019 Apr 3;14(4):e0214435. doi: 10.1371/journal.pone.0214435. eCollection 2019.

2. Graham CS, Swan T. A path to eradication of hepatitis $C$ in low and middle-income countries. Antiviral Res 2015;119:89-96.

3. Jacobson IM, Gordon SC, Kowdley KV, Yoshida EM, Rodriguez-Torres M, Sulkowski MS, et al. Sofosbuvir for 
hepatitis $\mathrm{C}$ genotype 2 or 3 in patients without treatment options. N England J Med 2013;368(20):1867-77.

4. European Association for the Study of the Liver. EASL recommendations on treatment of Hepatitis C 2014. J Hepatol 2014;61(2):373.

5. Lavanchy D. The global burden of hepatitis C. Liver Int 2009;29(1):74-8.

6. Esteban JI, Sauleda S, Quer J. The changing epidemiology of hepatitis $C$ virus infection in Europe. J Hepatol 2008;48(1):148-62.

7. Umar M, Bilal M. Hepatitis C, a mega menace: a Pakistani Perspective. J Pioneer Med Sci 2012;2(2):68-76.

8. Muhammad Umer, Mazhar Iqbal. Hepatitis C virus prevalence and genotype distribution in Pakistan: Comprehensive review of recent data. World J Gastroenterol 2016 January 28; 22(4): 1684-1700.

9. Falck-Ytter Y, Kale H, Mullen KD, Sarbah SA, Sorescu L, McCullough AJ. Surprisingly small effect of antiviral treatment in patients with hepatitis C. Ann Inter Med 2002;136(4):288-92.

10. Foster GR, Pianko S, Brown A, Forton D, Nahass RG George J, et al. Efficacy of sofosbuvir plus ribavirin with or without peginterferon-alfa in patients with hepatitis $C$ virus genotype 3 infection and treatment-experienced patients with cirrhosis and hepatitis C virus genotype 2 infection. Gastroenterology 2015;149(6):1462-70.

11. Ahmed OA, Kaisar HH, Hawash N, Samir H, Shabana SST, Hassan $A$, et al. Efficacy of sofosbuvir plus ribavirin with or without peginterferon-alfa in treatment of a cohort of Egyptian patients with hepatitis $\mathrm{c}$ virus infection. Infect Disord Drug Targets 2017;17(2):95-100.

12. Zeuzem S, Dusheiko GM, Salupere R, Mangia A, Flisiak R, Hyland $\mathrm{RH}$, et al. Sofosbuvir and ribavirin in HCV genotypes 2 and 3. N Engl J Med 2014;370(21):1993-2101.

13. Akhter TS, Umar M, Khaar HT, Aslam F, Nisar G, Naseer A et al. Sofosbuvir for the treatment of Hepatitis $C$ Genotype 3 infected patients in Pakistan. J Ayub Med Coll Abbott 2016;28(Suppl-1)(4):S884-9.

14. Shah SR, Chowdhury A, Mehta R, Kapoor D, Duseja A Koshy $A$, et al. Sofosbuvir plus ribavirin in treatment-naïve patients with chronic hepatitis $C$ virus genotype 1 or 3 infection in India. J Viral Hepat 2017;24(5):371-9.

15. Konar A, Chatterjee JG. SVR12 among 40 patients of chronic Hepatitis C treated with Sof/Rbv+/- Pegifn-result from a single tertiary center Kolkata, west Bengal. J Clin Exp Hepatol 2016;S14:1-2. 